\title{
Coconut Oil Extract Mitigates Testicular Injury Following Adjuvant Treatment with Antiretroviral Drugs
}

\author{
Oluwatosin 0 Ogedengbe ${ }^{1,2}$, Ayoola I Jegede ${ }^{1,3}$, Ismail O Onanuga ${ }^{1,4}$, Ugochukwu Offor ${ }^{1}$, \\ Edwin CS Naidu', Aniekan I Peter ${ }^{1,5}$ and Onyemaechi O Azu' \\ ${ }^{1}$ Discipline of Clinical Anatomy, Nelson R. Mandela School of Medicine, University of Kwazulu-Natal, Durban, South Africa \\ ${ }^{2}$ Department of Anatomy, College of Medicine and Health Sciences, Afe Babalola University, Ado Ekiti, Nigeria \\ ${ }^{3}$ Department of Anatomy, Faculty of Basic Medical Sciences, College of Health Sciences, \\ Ladoke Akintola University of Technology, Ogbomoso, Nigeria \\ ${ }^{4}$ Department of Anatomy, Faculty of Biomedical Sciences, Kampala International University, Western Campus, Ishaka, Uganda \\ ${ }^{5}$ Department of Anatomy, Faculty of Basic Medical Sciences, University of Uyo-Nigeria, Uyo, Nigeria
}

(Received May 17, 2016; Revised June 26, 2016; Accepted July 18, 2106)

\begin{abstract}
Increased access to highly active antiretroviral therapy (HAART) has made the management of drug toxicities an increasingly crucial component of HIV. This study investigated the effects of adjuvant use of coconut oil and HAART on testicular morphology and seminal parameters in Sprague- Dawley rats. Twelve adult male Sprague-Dawley rats, weighing 153 169 g were distributed into four groups (A-D) and treated as follows: A served as control (distilled water); B (HAART cocktail- Zidovudine, Lamivudine and Nevirapine); C (HAART + Virgin coconut oil $10 \mathrm{~mL} / \mathrm{kg}$ ) and D (Virgin coconut oil $10 \mathrm{~mL} / \mathrm{kg}$ ). After 56 days of treatment, animals were killed and laparotomy to exercise the epididymis for seminal fluid analyses done whilst testicular tissues were processed for histo-morphometric studies. Result showed a significant decline in sperm motility $(P<0.05)$ and count $(P<0.0001)$ in HAART-treated animals while there was insignificant changes in other parameters in groups $\mathrm{C}$ and $\mathrm{D}$ except count that was reduced $(P<0.0001)$ when compared with controls. Histomorphological studies showed HAART caused disorders in seminiferous tubular architecture with significant $(P<0.01)$ decline in epithelial height closely mirrored by extensive reticulin framework and positive PAS cells. Adjuvant Virgin coconut oil + HAART resulted in significant decrease in seminiferous tubular diameter $(P<0.05)$, but other morphometric and histological parameters were similar to control or Virgin coconut oil alone (which showed normal histoarchitecture levels). While derangements in testicular and seminal fluid parameters occurred following HAART, adjuvant treatment with Virgin coconut oil restored the distortions emanating thereof.
\end{abstract}

Key words: Histomorphology, Testis, Antiretroviral therapy, Andrology, Stains, Coconut oil

\section{INTRODUCTION}

The introduction of highly active antiretroviral therapy (HAART) in the management of HIV/AIDS have turned the tide from a high morbidity and mortality epidemic into a manageable chronic condition and thus making HAART the effective standard regimen $(1,2)$. HAART could be a dou-

Correspondence to: Onyemaechi O Azu, Discipline of Clinical Anatomy, Nelson R. Mandela School of Medicine, University of Kwazulu-Natal, Durban, South Africa

E-mail: azu@ukzn.ac.za

This is an Open-Access article distributed under the terms of the Creative Commons Attribution Non-Commercial License (http:// creativecommons.org/licenses/by-nc/3.0) which permits unrestricted non-commercial use, distribution, and reproduction in any medium, provided the original work is properly cited. ble or triple-drug cocktail with two nucleoside reverse transcriptase inhibitor (NRTI) backbones in combination with a non-nucleoside reverse transcriptase inhibitor (NNRTI), a protease inhibitor (PI) or an integrase strand transfer inhibitor (INSTIs) (3). The effective and efficient roll-out of HAART in South Africa, where the vast majority of HIVinfected individuals live, has contributed to the dramatic decline in morbity and mortality due to HIV/AIDS (4).

However, in spite of this success, there are still adverse effects incurred from HAART (5) including hepatotoxicity (6), nephrotoxicity (7) and neurotoxicity (8), following large-scale clinical trials on humans as well as animal experimental studies. In addition, there are concerns that the treatment-related drop in morbidity and mortality may actually be overestimated (4) as most studies relies on healthrelated quality of life outcomes considering only mortality 
and ignoring treatment-related morbidities.

Several reports have raised the possibility that long-term use of antiretroviral drugs may interrupt normal male reproductive function $(9,10)$. Clinical and animal experimental studies have ascertained the negative influence of HAART on sperm functional parameters, sexual hormones, testicular structure, germinal cell development, as well as testicular carbohydrate and lipid metabolism $(9,11)$. With the high financial burden of sustaining compliance with antiretroviral regimens, there is a major challenge of people living with HIV/AIDS (PLWHAs) (12) most especially among sub-Saharan Africa necessitating majority of them resorting to the use of traditional medicines and products $(13,14)$ for improvement of their well-being. Besides, scientific interest towards the use of medicinal plants has been on the rise due to their perceived effectiveness during treatment, relatively low costs and minimal side-effects (15).

Cocos nucifera (Coconut) is an important fruit that is grown in most tropical and subtropical regions of the world (16) and has been referred to as the 'tree of life due to its' several applications (17). Its part includes the husks, coconut water, coconut meat, coconut milk and coconut oil and have been linked to numerous medicinal properties (18). There are reports of its use as alternative medicinal therapy $(19,20)$ for treatment of diabetes, diarrhea and as anticancer (20) using in vitro and in vivo techniques.

Virgin coconut oil (VCO) is extracted from fresh coconut (20) and differs from ordinary coconut oil because it contains more biologically active components of polyphenols, tocopherols, sterols and squalene (21). It has captured a lot of interest due to its ability to mitigate oxidative stressrelated processes via inhibition of lipid peroxidation (22). Reports of its improvement of semen quality (sperm counts and motility) as well as boosting serum testosterone levels (23) have been acknowledged. Though VCO has many therapeutic values, there are no scientific reports on its ability to mitigate testicular injuries associated with any HAART either in human and/or experimental animal model. This present study therefore investigated the possible ameliorative effects of VCO as adjuvant with ART with the view to mitigating the ravages of HAART on testicular tissues using an animal (male Sprague-Dawley rats) model.

\section{MATERIALS AND METHODS}

Twenty adult male Sprague-Dawley rats, weighing 153 $169 \mathrm{~g}$ were used for this study. These animals were bred and maintained at the Animal House of the Biomedical Resources Unit, University of Kwazulu-Natal. All procedures involving the animals was performed in accordance with the Principle of Laboratory Animal Care of the National Medical Research Council and the Guide for the Care and Use of Laboratory Animals (24). The protocol for the study was approved by Animal Ethics Committee (protocol reference number: AREC/087/015D). The rats had unrestricted access to food (standard rat pellets) and water.

All the rats were housed in plastic cages ( 3 rats/cage) having dimensions of 30 long, 20 wide and $13 \mathrm{~cm}$ high) and soft wood shavings employed as bedding in the cages. Rats were maintained under standardized animal house conditions (temperature: $28 \sim 31^{\circ} \mathrm{C}$; light: approximately $12 \mathrm{hr}$ natural light per day; humidity: 50 55\%). The drug Zidovudine, Lamivudine, and Nevirapine (Aspen) were procured from Pharmed, Durban, South Africa.

Plant material. The solid endosperm of mature coconuts were commercially purchased from a local store in Durban area and were authenticated at the Department of Life Science, Westville Campus, University of KwazuluNatal, South Africa.

Preparation of VCO. The wet extraction method described by Nevin and Rajamohan (22) was used for VCO extraction. Briefly, the solid, matured coconut were crushed and made into viscous slurry, water of about $500 \mathrm{~mL}$ was added and squeezed through cheese cloth to obtain coconut milk. The coconut milk produced was left for about $24 \mathrm{hrs}$ to aid the gravitational separation of the milk, which was in accordance with $(25,26)$. Three phases resulted; a lower aqueous phase, a middle emulsion phase, and an upper oily phase. The upper oily phase was then decanted and heated for about $10 \mathrm{~min}$ to remove moisture. The resultant VCO was then filtered with a fine sieve, stored in plain bottles at room temperature and used for the experiment.

Experimental design: The animals were randomly distributed into four (4) groups (A-D) and treated as follows:

A (control animals received distilled water).

B (HAART cocktail of Zidovudine, Lamivudine and Nevirapine adjusted to the equivalent animal dose of 1.89 , 0.95 and $1.26 \mathrm{mg} / \mathrm{kg}$ body weight respectively) (27).

$\mathrm{C}$ (HAART + VCO $10 \mathrm{~mL} / \mathrm{kg})$.

$\mathrm{D}$ (VCO $10 \mathrm{~mL} / \mathrm{kg})$.

All treatment was applied daily by oro-gastric gavage and at the end of 56 days all animals were killed 24 hrs after the last treatment under halothan $\mathrm{e}^{\mathrm{R}}$ anesthesia.

Body and testicular weight. The body weights of animals were recorded on the first day before treatment (initial), thereafter on a weekly basis and finally on the last day of experiment. The weight of the testes (TW) was measured by an electronic balance (Mettler Toledo; Microsep (Pty) Ltd., Greifensee, Switzerland). The testes of each rat were measured individually and the average value obtained for each of the two testes were regarded as one observation. The values are expressed in grams $(\mathrm{g})$ for TW.

Semen analysis. The caudal epididymis of the rats were excised and minced with an anatomical scissors, a 
drop of epididymal fluid was collected onto a glass slide, covered with cover slip covered with a $22 \times 22 \mathrm{~mm}$ cover slip and examined under a light microscope (28). The microscopic field was scanned systematically and the motility of each spermatozoa encountered was assessed (29), motility was graded as progressive, non-progressive and dead (30). After assessing different microscopic fields, the relative percentage of motile sperm was estimated and reported to the nearest $5 \%$ using the subjective determination of motility (31).

The epididymal tissue was cut into small pieces and diluted with normal saline and sperm count was determined using an automated sperm analyser with a double slide counting chamber. The dilution was mixed thoroughly and both sides of the counting chamber were scored and the average taken. The number of spermatozoa counted was expressed in millions $/ \mathrm{mL}$ (31).

Histomorphometrical and histochemical studies. Each testis was removed, trimmed of attached tissues and weighed. The testis was fixed in $10 \%$ Neutral buffered formalin and processed for histological and histochemical evaluations.

For routine histological study, the testis were dehydrated in an alcohol series of $100 \%, 90 \%, 70 \%, 50 \%$, cleared in xylene, infiltrated and embedded in paraffin and then sectioned ( $4 \mu \mathrm{m}$ thick) using a microtome (microm HM 315 microtome, Walldorf, Germany). They were further deparaffinised, stained with hematoxylin and eosin (H\&E). For histochemical studies, the tissues were stained with Periodic acid schiff (PAS) technique for the detection of glycogen, neutral polysaccharides and basement membrane; Gordon and Sweet's silver staining method to demonstrate reticular fibers (32). Examination of the stained tissue sections was done by a histopathologist who was blinded to the study protocol.

For morphometric analyses, seven vertical sections from the polar and the equatorial regions were sampled and an unbiased numerical estimation of the following morphometric parameters (diameter and cross-sectional area of the seminiferous tubules, seminiferous epithelial height/thickness) was determined using systematic random scheme (33). The seven vertical sections were selected by a systematic sampling method that ensured fair distribution between the polar and equatorial regions of each testis. The diameters (D) of approximately 18 randomly selected seminifer- ous tubules with profiles that were round or nearly round was measured for each slide and a mean D was determined by taking the average of two diameters, D1 and D2. D1 and $\mathrm{D} 2$ were taken only when $\mathrm{D} 1 / \mathrm{D} 2 \geq 0.85(1.0=$ a perfect circle). This is to eliminate longitudinal profiles which might exhibit different degrees of damage along their length and/ or show irregular shrinkage as previously reported $(33,34)$. The tubular diameter and height of the seminiferous tubule epithelium was scanned using Leica SCN 400 (Leica Microsystems $\mathrm{GmbH}$, Wetzlar, Germany) and measured at X 100 magnification using image analyser Leica (DMLB) and Leica microsystem software. The diameter of the seminiferous tubule was measured across the minor and major axes, and the mean diameter obtained as stated above. Cross-sectional area (AC) of the seminiferous tubules was determined from the formula, $A_{C}=\pi D^{2} / 4$ (where $\pi$ is equivalent to 3.142 and $\mathrm{D}$ is the mean diameter of the seminiferous tubules).

Statistical analysis. The morphometric data were analysed using parametric methods. The results are expressed as mean standard error of mean. These were then subjected to within and between group differences using one way ANOVA, followed by Dunnett's multiple comparison test, which was performed using GraphPad Prism version 5.00 for Windows, GraphPad Software, San Diego, CA, USA.

\section{RESULTS}

Organ-body weight changes. There was a general insignificant increase in body weight of animals in all groups but this increase was least in group $\mathrm{D}$ compared with the control group A. Significant decrease $(p<0.05)$ in percentage body weight of group D animals compared with control was observed $(34.64 \pm 3.80$ vs. $51.61 \pm 5.49)$. The testicular weight (TW) of all the treated groups B, C and D were similar to that of the control. There was insignificant difference $(P>0.05)$ in the relative organ weight $(\mathrm{TW} / \mathrm{BW} \times 100)$ in all the treated groups $(\mathrm{B}, \mathrm{C}$ and $\mathrm{D})$ when compared with control group A (Table 1).

Changes in semen parameters. There was a highly significant decrease $(p<0.0001)$ in mean sperm count in animals treated with HAART $\left(0.74 \pm 0.30 \times 10^{6} / \mathrm{mL}\right)$, HAART + VCO $\left(0.93 \pm 0.34 \times 10^{6} / \mathrm{mL}\right)$ and VCO $(1.86 \pm$

Table 1. Body weight, testicular weight and TW/BW ratio in groups

\begin{tabular}{clccccc}
\hline \hline Grp & Initial Bw $(\mathrm{g})$ & Final Bw $(\mathrm{g})$ & Weight Diff $(\mathrm{g})$ & Difference $(\%)$ & TW $(\mathrm{g})$ & TW/BW $\times 100$ \\
\hline A & $216.70 \pm 5.93$ & $328.70 \pm 16.80$ & $112.0 \pm 13.05$ & $51.61 \pm 5.49$ & $3.30 \pm 0.01$ & $1.01 \pm 0.05$ \\
B & $232.70 \pm 13.86$ & $364.00 \pm 24.64$ & $131.3 \pm 11.46$ & $56.34 \pm 2.44$ & $3.40 \pm 0.11$ & $0.93 \pm 0.05$ \\
C & $240.70 \pm 8.33$ & $325.70 \pm 18.19$ & $85.0 \pm 11.68$ & $35.18 \pm 4.10$ & $3.36 \pm 0.29$ & $1.03 \pm 0.03$ \\
D & $222.70 \pm 4.67$ & $300.00 \pm 13.00$ & $77.3 \pm 9.39$ & $34.64 \pm 3.80^{*}$ & $3.41 \pm 0.10$ & $1.14 \pm 0.15$ \\
\hline
\end{tabular}

*Statistically significant at $p<0.05$. 
$\left.0.54 \times 10^{6} / \mathrm{mL}\right)$ respectively when compared with control $\left(5.67 \pm 0.26 \times 10^{6} / \mathrm{mL}\right)$. In addition HAART significantly lowered the progressive sperm motility of group B animals when compared with the control $(p<0.05)(46.67 \pm 6.67 \%$ vs. $71.33 \pm 4.67 \%$ ). An insignificant increase in progressive motility was observed in group D animals $(p>0.05)$ when compared with the control group $(74.00 \pm 7.02 \%$ vs. $71.33 \pm$ $4.67 \%$ ). On the other hand, a significant increase in nonprogressive motility $(p<0.05)$ was observed in group B when compared to control group A $(31.33 \pm 4.67 \%$ vs. $16.67 \pm$ $3.33 \%$ ). Similarly, adjuvant HAART + VCO restired sperm motility to almost control values with \% non-progressive motility and dead spermatozoa almost similar to VCOalone and control groups (Fig. 1).

There were no animal deaths recorded during the experimental period.

Morphological parameters. The diameter of seminiferous tubules in HAART + VCO animals showed a significant decrease $(p<0.05)$ whereas HAART-alone animals showed insignificant decrease $(P>0.05)$ compared with the control group A $(266.10 \pm 6.23 \mu \mathrm{m}$ vs. $294.50 \pm 8.04 \mu \mathrm{m})$. Geminal epithelial thickness (ET) of seminiferous tubules showed a significant decrease in HAART group compared to that in control $(P<0.01)$. However, in adjuvant HAART + $\mathrm{VCO}$ and VCO-alone groups recorded no significant alterations in this parameter. The cross-sectional areas of seminiferous tubules of group $\mathrm{C}$ treated with a combined dose of HAART + VCO was significantly lowered $(p<0.05)$ when compared with the control group A $(55.88 \pm 2.60$ vs. 68.59 $\mu \mathrm{m}^{2} \pm 3.79 \mu \mathrm{m}^{2}$ ) (Fig. 2).

Histological and histochemical results. Results of testicular section staining using H\&E, PAS and Gordon and Sweet's silver methods revealed varying effects of treatment on the tissues. Testicular cross section of control and VCO groups showed essentially well preserved cyto-architecture and microanatomy of the testes with seminiferous tubules (ST) populated by spermatogenic cells at various stages of development. The interstitial spaces were normal with Leydig cells clearly visible and no infiltrations. In many of the ST of HAART-alone and HAART + VCO
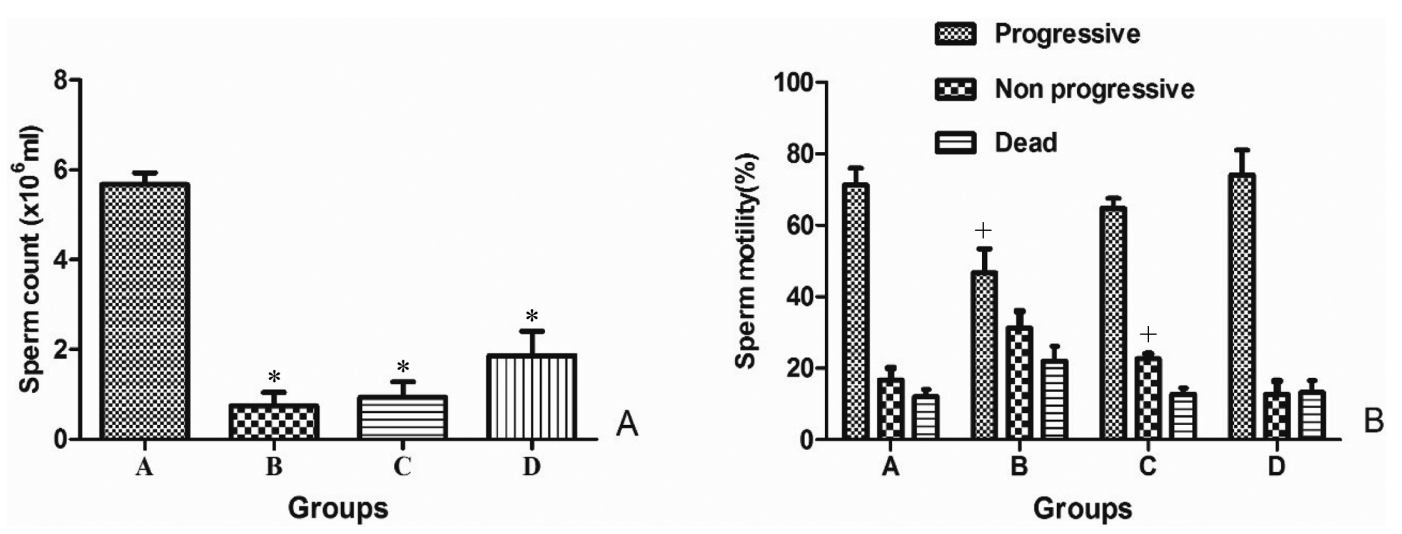

Fig. 1. Effect of VCO and HAART treatment on sperm count and motility in Sprague-Dawley rats after 8 week-treatment period. Bars indicate the mean $\pm \mathrm{SEM} ;{ }^{*} P<0.0001 ;{ }^{+} P<0.05$.
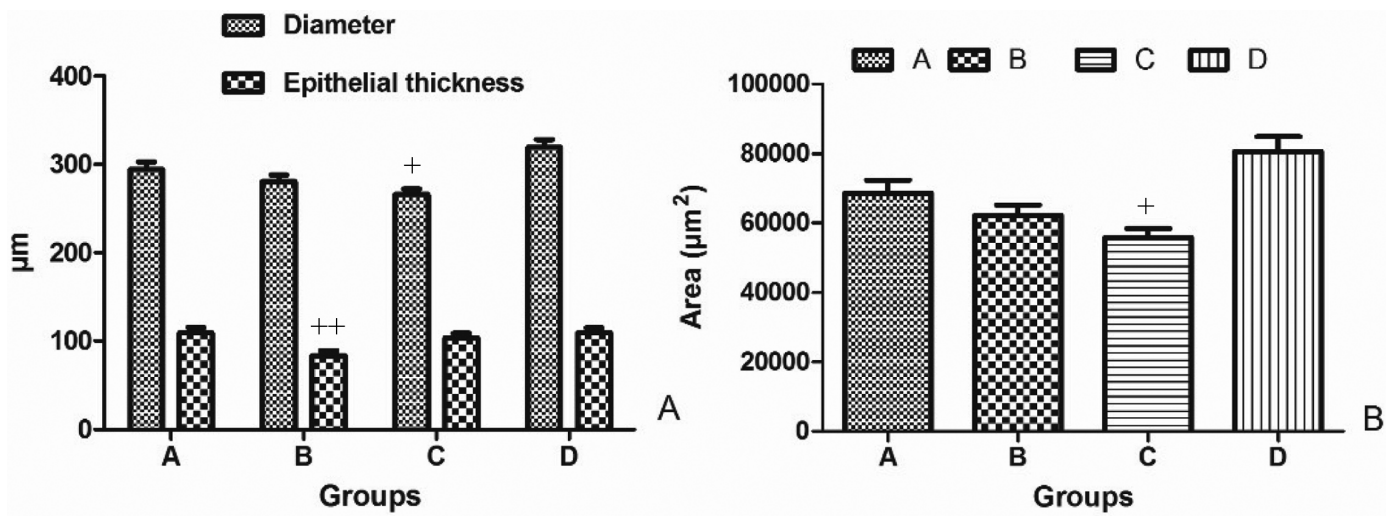

Fig. 2. Effect of VCO and HAART treatment on diameter, epithelial thickness and area in Sprague-Dawley rats after 8 week-treatment period. Bars indicate the mean $\pm \mathrm{SEM} ;{ }^{+} P<0.05 ;{ }^{++} P<0.001$. 

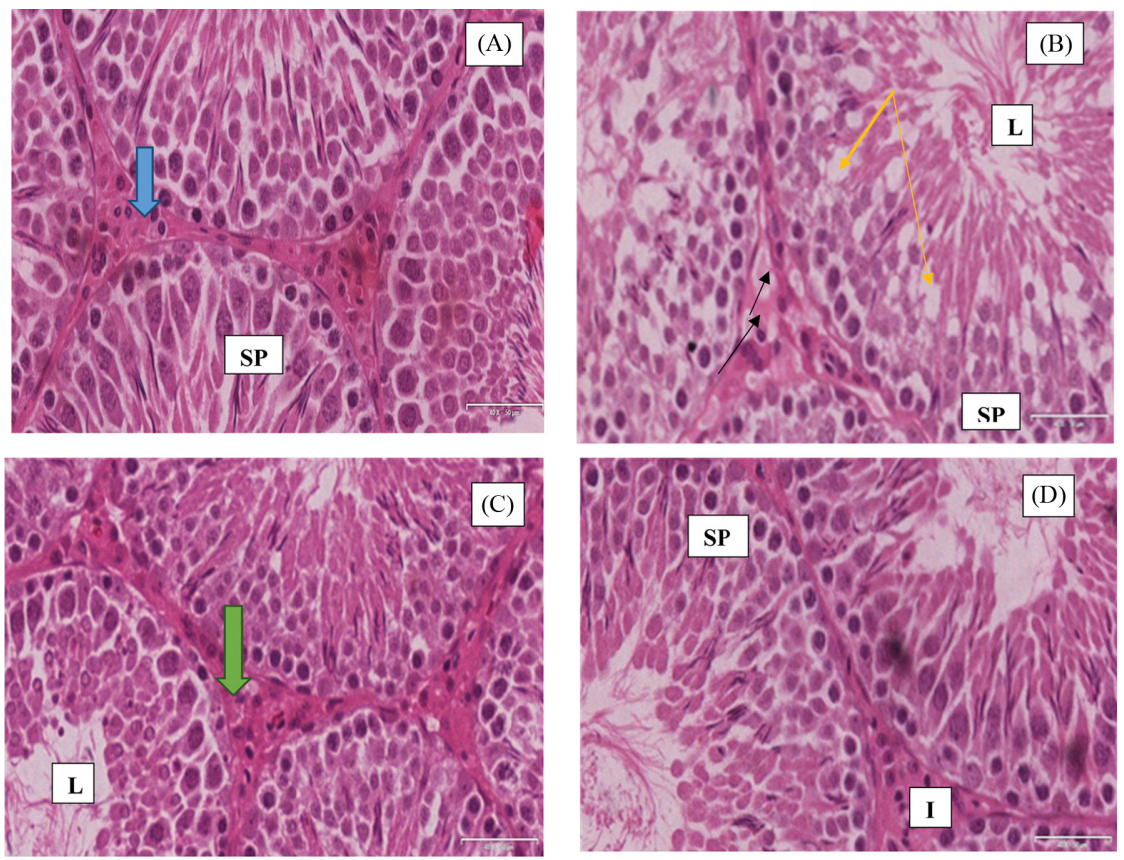

Fig. 3. Micrograph of testicular histological section of groups (A), (B), (C) and (D) (H \& E). Control animals (A) and (D) (VCO) shows seminiferous tubules with normal architecture and spermatogenic cells (SP). The interstitial spaces (I) with Leydig cells are normal. The lumen (L) is also populated by immotile spermatozoa. Note the hypoplastic changes with vacuolations (arrowed) in some of the seminiferous tubules in slide (B). There are also reduced spermatogenic cell series in tubules. In (C) (HAART + VCO), partial restoration in some seminiferous tubules was evident.
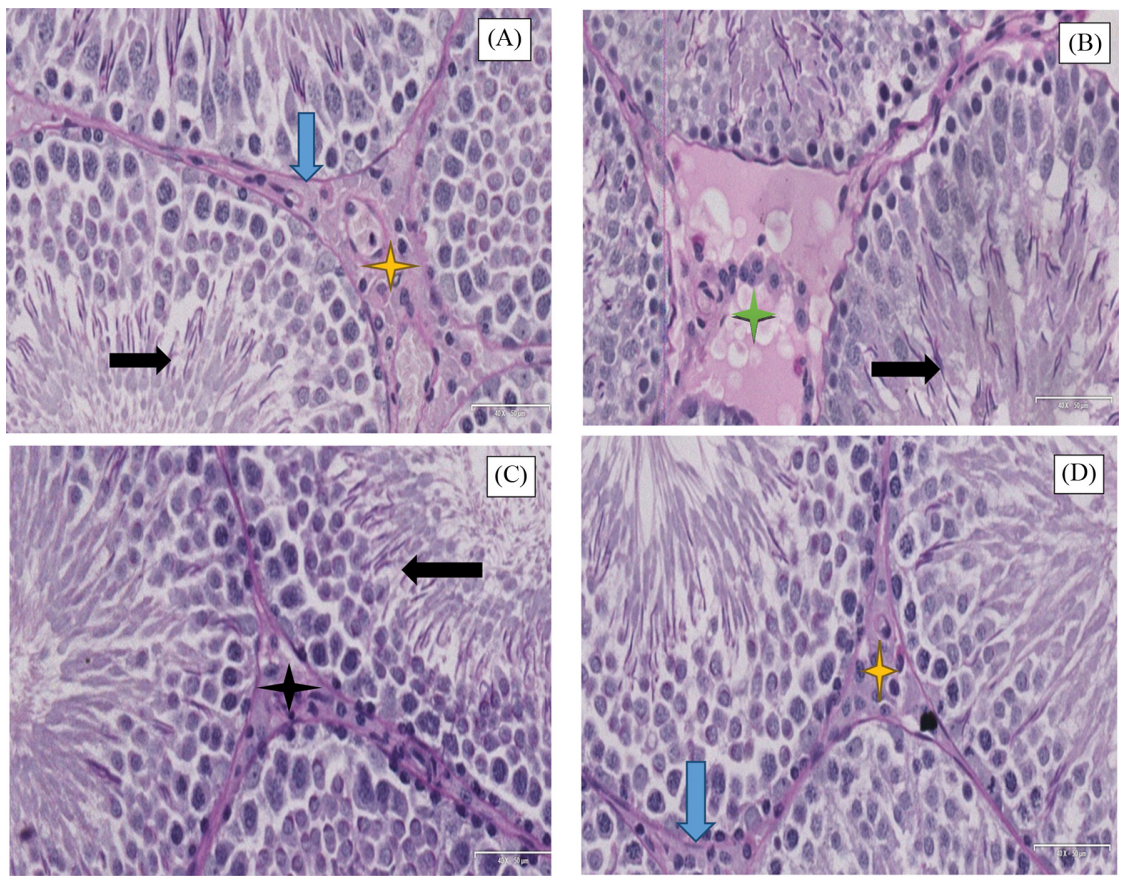

Fig. 4. Micrograph of testicular section of groups (A), (B), (C) and (D) (PAS). The basal membrane of the seminiferous tubule (blue arrow) has normal thickness, the basement membrane and the upper series of germinal epithelium exhibits a positive PAS reaction. The intensity of PAS is higher in (B) and (C). Note in slide (B) the few number of Leydig cells and the peritubular interstitial tissue presenting weak reaction with PAS (green star ${ }^{*}$ ). In $(C)$ there is also a strong peritubular interstitial tissue reaction with PAS compared with other slides (black star ${ }^{*}$ ). Yellow star $\left(^{*}\right)$ in $(A)$ and $(C)$ there is normal peritubular interstitial tissue reaction with PAS. Black arrow shows acrosome stained with PAS. 

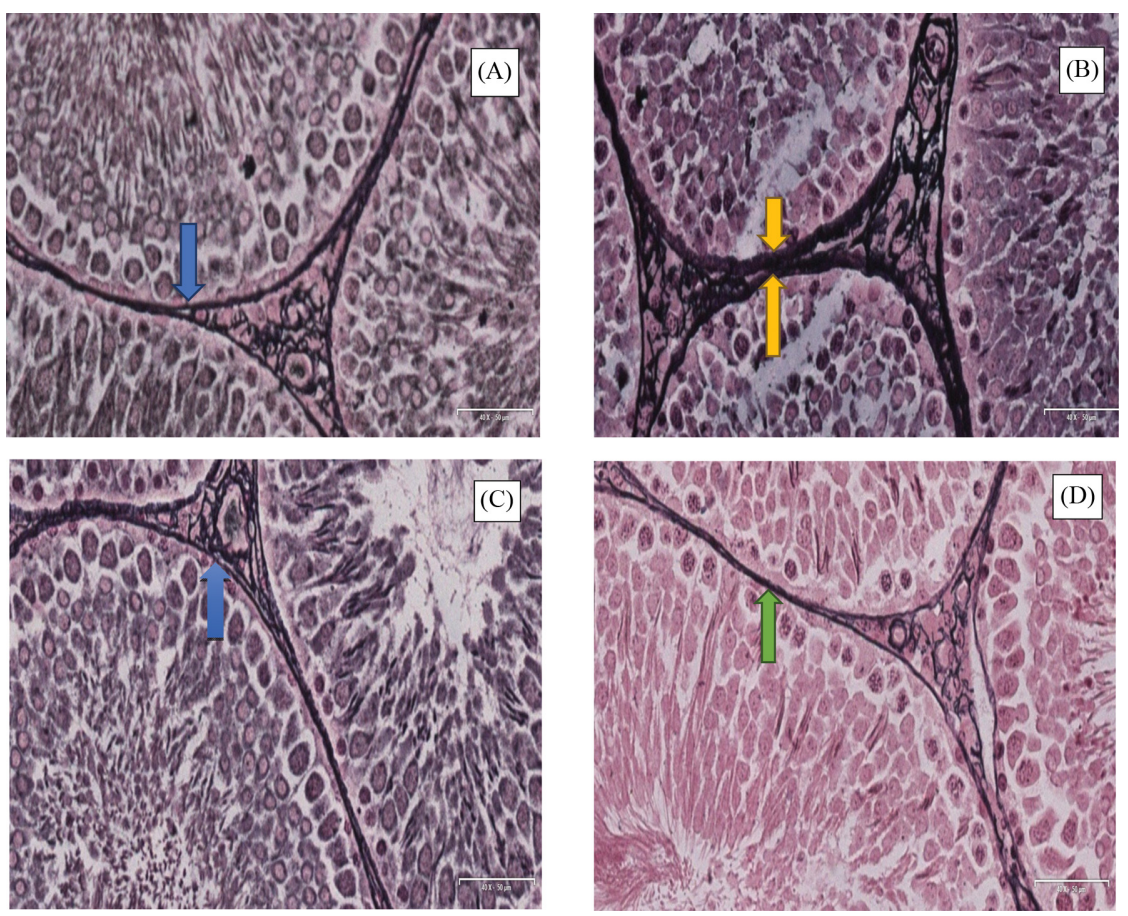

Fig. 5. Micrograph of testicular section of groups (A), (B), (C) and (D) (Gordon and Sweet's) demonstrating reticular fibres (arrowed). Note the thickened basement membrane in (B) with fine threads around (A) and (D). Slides (A) and (D) show well preserved reticular connective tissue (black coloured stain).

groups, there were gross hypoplastic changes in many ST of the former with additional vacuolar changes more numerous in the later. These observations relates with the reduced and disorganized spermatogenic cells in many ST of HAART-treated animals with only basal spermatogonia in some ST. There were less architectural distortions in adjuvant VCO + HAART testis (Fig. 3).

In the current study, the cytoplasm of Leydig cell, peritubular interstitial tissues and basement membrane reacts positively with PAS. PAS-stained sections reveal glycogen presence in the tissues and is depicted by pink color in the sections. Sections from control animals showed clear and positive PAS-reaction with pink-stained thin basement membranes around ST as well as upper series of the seminiferous epithelium and acrosomal caps of matured spermatozoa. There were significant increase in PAS positive particles in slides B and C compared with control and VCO groups. While the PAS stain demonstrates glycogen, indications for distortion in ST cells were evident in the intensity as well with HAART-group exhibiting most staining intensity (Fig. 4).

Silver impregnation with the Gordon and Sweet's method revealed the presence of unique dark-stained reticulin fibres around ST basement membranes and connective tissues in the interstitial spaces in slides from groups $\mathrm{A}$ and D. In HAART-treated group, extensive meshwork of thickened, dark-stained fibres were clearly visible around ST basement membranes and sections from group $\mathrm{C}$ also exhibited similarity with HAART group but to a lesser degree indicating restoration to control and VCO groups. The massive loss of germ cells (primary and secondary spermatocytes) in HAART group compared with HAART + VCO is visibly present with only basal spermatogonia cells present in the former (Fig. 5).

\section{DISCUSSION}

In the last decade, the positive impact of combination antiretroviral therapy on the reduction of HIV-associated mortality and morbidity cannot be underscored despite challenging pitfalls with therapy. Besides, the intolerable side effects of HIV medications can emanate from failure due to drug-drug interactions, organ specific toxicity and/or non-adherence (35). In other to mitigate some of the unwanted side effects of HAART, PLWHAs in sub-Saharan Africa rely on medicinal plants rich in biologically active components for alleviation of some of the toxicities of HAART (36). Reports by (37) and (38) corroborates the use of complimentary alternative medicine for alleviation of pain in PLWHAs. Many herbal extracts are known to exert protective action against noxious effects of toxicants/drugs on organs by their ability to decrease oxidative damage-mediated pathologies (40). VCO has been reported to have active and large amounts of polyphenols and tocopherols which are powerful counter measures against lipid peroxi- 
dation $(39,41)$ in tissues. Therefore, as compelling evidence suggests that HAART amplifies oxidative stress status in PLWHAs $(42,43)$, the current study therefore demonstrates the possible protective role of $\mathrm{VCO}$ in the mitigation of HAART's ravages on testicular parameters.

We report, for the first time, that adjuvant treatment with VCO mitigates the intensive histopathological changes and loss of considerable number of germ cells in seminiferous tubules of rats due to HAART. The decrease in seminiferous epithelial layers may be linked to inhibitive processes against spermatogonium B that elongates the G-1 phase of spermatogenic cycle (44). In our experiment, adjuvant treatment of VCO had a protective effect on the seminiferous epithelium as demonstrated by the lowering of degeneration and restitution of normal epithelial lining. Testicular sections of HAART-treated animals showed extensive fibrosis around basement membranes of ST (seen with silver impregnation) which are suggestive that disturbances between the Sertoli cells and basement membrane cells (myoid) may have been drastically altered with consequent fibrotic reaction and possible hyalinization (45).

Decreased ET and ST diameter are a result of reduced metabolic activity of the germinal cells as well as cell numbers with the consequence that interstitial spaces widen with oedematous appearance (46). Several studies that have examined HAART effects on semen parameters and other morphometric features of the testis $(9,47)$, have supported our overall result indicating HAART-induced distortions do occur by changes in morphology and morphometric indices of the testis. These ravages were ameliorated by VCO possibly due to its rich antioxidative properties as previously stated by (48). Putatively, pathways for the generation of reactive oxygen species leading to oxidative stress and toxicity of HAART relies on mitochondria-related perturbations that manifests in many side effects such as hepatic failure and lactic acidosis (49). The 'mitochondrial dysfunction hypothesis' reviewed in (50) is believed to operate via energy deprivation, mitochondrial oxidative stress and consequent mitochondrial DNA damage. With depleted energy reserve (observed by significantly reduced progressive motility and increased non-progressive motility in HAART-treated group), mitochondria are unable to execute the needed forward propulsive motion necessary to achieve fertilization and NRTIs and PIs have been implicated as major culprits $(49,51)$. Whilst this protocol did not report perturbations in antioxidant enzymes, previous animal studies on VCO (48) supports the ability of VCO to increase the activity of antioxidant enzymes (e.g. catalase, superoxide dismutase, etc.) in tissues with consequent decline in formation of lipid peroxidation products. Spermatozoa motility is dependent on a robust energy supply and a jealously-guarded polyunsaturated fatty acid membrane prone to oxidative stress mediated damage. With adjuvant VCO + HAART, these negative effects were mitigated in this study.
There was no significant difference in the percentage weight difference of the animal in the control and treatment group except animals in the group administered with only VCO. This might have been due to the fact that VCO contains saturated fatty acids which may likely cause softening of stools and diarrhea that may have caused weight loss (52), although we did not measure any parameter in this regard.

In the current study, $\mathrm{VCO}$ at $10 \mathrm{~mL} / \mathrm{kg}$ dose resulted in an increase in parameters including ST diameter (though not significantly different with control). Though progressive sperm motility was higher and non-progressive motility lowest compared to other groups, these values were not significant. However, the positive indices reflects the ability of VCO to ameliorate toxicant injuries to the testis. Previous reports have pointed to the unsaponifiable components of VCO like vitamin E and polyphenols playing a beneficial role in reducing cholesterol levels and lipid peroxidation (53). It is very likely that this postulation may be operational in our scenario.

The increased PAS positive particles (which are carbohydrate components) in cells seen in sections of tissues from groups $\mathrm{C}$ and $\mathrm{D}$ alongside the thickened basement membrane and silver stained reticulin network in HAARTtreated groups all points towards a metabolic disorder of testicular cells. While Sertoli cells provide the bare cytoskeletal framework for ST, they also assist in phagocytosis of dead/or degenerating spermatogenic cells (47). Many of the ST in sections from HAART group showed Sertoli cells with dense congregations as inclusions. While we did not report assay of testosterone in this study, the results from derangements in seminal and morphological data following antiretroviral therapy evidently implicates altered testicular androgen levels hence impairment in spermatogenic processes as discussed in (9). Calvin et al. (54) have suggested that the metabolic pathway of testosterone synthesis requires protection against lipid peroxidation of which the polyphenols present in VCO have been recognized as a powerful counter measure. Taken together, these observations tallies with morphometric data and thus supports the positive role of VCO in this experiment.

In summary, HAART regime as used in this protocol can lead to testicular damage and sperm abnormalities and VCO extract has potential of ameliorating this deleterious effects and protecting the testis through its antioxidant properties. Further studies are needed to understand the precise mechanistic pathway through which this action is dissipated on testicular tissue.

\section{ACKNOWLEDGMENTS}

The College of Health Sciences, University of KwaZuluNatal is acknowledged for postgraduate support to first author. 


\section{CONFLICT OF INTEREST}

None declared by all authors.

\section{REFERENCES}

1. Bachanova, V. and Connors, J.M. (2016) Hodgkin lymphoma in the elderly, pregnant, and HIV-infected. Semin. Hematol., 53, 203-208.

2. Greenberg, K.I., Perazella, M.A. and Atta, M.G. (2015) HIV and HCV medications in end-stage renal disease. Semin. Dial., 28, 397-403.

3. Scientific Coordination Committee, Marcotullio, S., Andreoni, M., Antinori, A., d'Arminio Monforte, A., Di Perri, G., Galli, M., Ippolito, G., Perno, C.F., Rizzardini, G. and Lazzarin, A.; Rapporteur Committee, Cinque, P., Fares, G., Foglia, E., Gervasoni, C., Murri, R., Nozza, S. and Rusconi S. (2012) The Less Drugs Regimens (LDRs) therapy approach in HIV1: an Italian expert panel perspective for the long-term management of HIV-1 infection. New Microbiol., 35, 259-277.

4. Pitt, J., Myer, L. and Wood, R. (2009) Quality of life and the impact of drug toxicities in a South African community-based antiretroviral programme. J. Int. AIDS Soc., 12, 5.

5. Nagiah, S., Phulukdaree, A. and Chuturgoon, A. (2015) Mitochondrial and oxidative stress response in HepG2 cells following acute and prolonged exposure to antiretroviral drugs. J. Cell. Biochem., 116, 1939-1946.

6. Casado, J., Mena, A., Bañón, S., Castro, A., Quereda, C., Moreno, A., Pedreira, J. and Moreno, S. (2016) Liver toxicity and risk of discontinuation in HIV/hepatitis $\mathrm{C}$ virus-coinfected patients receiving an etravirine-containing antiretroviral regimen: influence of liver fibrosis. HIV Med., 17, 62-67.

7. da Rocha, I.M., Gasparotto, A.S., Lazzaretti, R.K., Notti, R.K., Sprinz, E. and Mattevi, V.S. (2015) Polymorphisms associated with renal adverse effects of antiretroviral therapy in a Southern Brazilian HIV cohort. Pharmacogenet. Genomics, 25, 541-547.

8. Dorsey, J.L., Mangus, L.M., Hauer, P., Ebenezer, G.J., Queen, S.E., Laast, V.A., Adams, R.J. and Mankowski, J.L. (2015) Persistent peripheral nervous system damage in simian immunodeficiency virus-infected macaques receiving antiretroviral therapy. J. Neuropathol. Exp. Neurol., 74, 1053-1060.

9. Azu, O.O., Naidu, E.C., Naidu, J.S., Masia, T., Nzemande, N.F., Chuturgoon, A. and Singh, S. (2014) Testicular histomorphologic and stereological alterations following short-term treatment with highly active antiretroviral drugs (HAART) in an experimental animal model. Andrology, 2, 772-779.

10. Adaramoye, O.A., Akanni, O.O., Adewumi, O.M. and Owumi, S.E. (2015) Lopinavir/ritonavir, an antiretroviral drug, lowers sperm quality and induces testicular oxidative damage in rats. Tokai J. Exp. Clin. Med., 40, 51-57.

11. Pathak, A., Meena, L.P., Chakravarty, J., Rai, M. and Sundar, S. (2015) A pilot study to evaluate the effect of HAART on gonadal dysfunction in male HIV patients. Natl. J. Physiol. Pharm. Pharmacol., 5, 33-35.

12. Boyer, S., Clerc, I., Bonono, C.R., Marcellin, F., Bilé, P.C. and Ventelou, B. (2011) Non-adherence to antiretroviral treatment and unplanned treatment interruption among people living with HIV/AIDS in Cameroon: Individual and healthcare supply-related factors. Soc. Sci. Med., 72, 1383-1392.

13. Langlois-Klassen, D., Kipp, W., Jhangri, G.S. and Rubaale, T. (2007) Use of traditional herbal medicine by AIDS patients in Kabarole District, western Uganda. Am. J. Trop. Med. Hyg., 77, 757-763.

14. Mudzviti, T., Maponga, C.C., Khoza, S., Ma, Q. and Morse, G.D. (2012) The impact of herbal drug use on adverse drug reaction profiles of patients on antiretroviral therapy in zimbabwe. AIDS Res. Treat., 2012, 434171.

15. Jaarin, K., Norliana, M., Kamisah, Y., Nursyafiza, M. and Qodriyah, H.M.S. (2014) Potential role of virgin coconut oil in reducing cardiovascular risk factors. Exp. Clin. Cardiol., 20, 3399-3410.

16. Dixon, G.R. and Aldous, D.E. (2014) Horticulture: plants for people and places. production horticulture, Springer, Dordrecht.

17. DebMandal, M. and Mandal, S. (2011) Coconut (Cocos nucifera L.: Arecaceae): in health promotion and disease prevention. Asian. Pac. J. Trop. Med., 4, 241-247.

18. Prades, A., Dornier, M., Diop, N. and Pain, J.P. (2012) Coconut water uses, composition and properties: a review. Fruits, 67, 87-107.

19. Mantena, S.K., Jagadish, Badduri, S.R., Siripurapu, K.B. and Unnikrishnan, M.K. (2003) In vitro evaluation of antioxidant properties of Cocos nucifera Linn. water. Nahrung, 47, 126131.

20. Law, K.S., Azman, N., Omar, E.A., Musa, M.Y., Yusoff, N.M., Sulaiman, S.A. and Hussain, N.H. (2014) The effects of virgin coconut oil (VCO) as supplementation on quality of life (QOL) among breast cancer patients. Lipids Health Dis., 13, 139.

21. Abujazia, M.A., Muhammad, N., Shuid, A.N. and Soelaiman, I.N. (2012) The effects of virgin coconut oil on bone oxidative status in ovariectomised rat. Evid. Based Complement. Alternat. Med., 2012, 525079.

22. Nevin, K.G. and Rajamohan, T. (2006) Virgin coconut oil supplemented diet increases the antioxidant status in rats. Food Chem., 99, 260-266.

23. Dosumu, O.O., Akinola, O.B. and Akang, E.N. (2012) Alcohol-induced testicular oxidative stress and cholesterol homeostasis in rats - The therapeutic potential of virgin coconut oil. Middle East Fertil. Soc. J., 17, 122-128.

24. National Research Council (US) Committee for the Update of the Guide for the Care and Use of Laboratory Animals (2011) Guide for the care and use of laboratory animals (8th edition), National Academies Press (US), Washington.

25. Onsaard, E., Vittayanont, M., Srigam, S. and McClements, D.J. (2005) Properties and stability of oil-in-water emulsions stabilized by coconut skim milk proteins. J. Agric. Food Chem., 53, 5747-5753.

26. Nour, A.H., Mohammed, F., Yunus, R.M. and Arman, A. (2009) Demulsification of virgin coconut oil by centrifugation method: a feasibility study. Int. J. Chem. Technol., 1, 5964.

27. Umar, R., Hassan, S., Ladan, M., Matazu, I., Shehu, B., Shehu, R., Muhammed, L. and Molabo, F. (2008) Adverse hepatic effects associated with administration of antiretroviral drugs (nevirapine, lamivudine and stavudine) to albino rats: 
Implication for management of patients with HIV/AIDS. Asian J. Biochem., 3, 19-25.

28. Organization, W.H. (1999) WHO laboratory manual for the examination of human semen and sperm-cervical mucus interaction, Cambridge university press.

29. Rizk, B.R. and Sallam, H.N. (2012) Clinical infertility and in vitro fertilization, Jaypee Brothers Medical Pub.

30. Vasan, S.S. (2011) Semen analysis and sperm function tests: How much to test? Indian J. Urol., 27, 41-48.

31. Keel, B.A. and Webster, B.W. (1990) Handbook of the laboratory diagnosis and treatment of infertility, CRC Press.

32. Bancroft, J.D. and Gamble, M. (2008) Theory and practice of histological techniques, Elsevier Health Sciences.

33. Gundersen, H.J. and Jensen, E.B. (1987) The efficiency of systematic sampling in stereology and its prediction. $J$. Microsc., 147, 229-263.

34. Christensen, A.K. and Peacock, K.C. (1980) Increase in Leydig cell number in testes of adult rats treated chronically with an excess of human chorionic gonadotropin. Biol. Reprod., 22, 383-391.

35. Di Biagio, A., Cozzi-Lepri, A., Prinapori, R., Angarano, G., Gori, A., Quirino, T., De Luca, A., Costantini, A., Mussini, C., Rizzardini, G., Castagna, A., Antinori, A., d'Arminio Monforte, A.; ICONA Foundation Study Group. (2016) Discontinuation of initial antiretroviral therapy in clinical practice: moving towards individualized therapy. J. Acquir. Immune Defic. Syndr., 71, 263-271.

36. Vermani, K. and Garg, S. (2002) Herbal medicines for sexually transmitted diseases and AIDS. J. Ethnopharmacol., 80, 49-66.

37. Tsao, J.C., Dobalian, A., Myers, C.D. and Zeltzer, L.K. (2005) Pain and use of complementary and alternative medicine in a national sample of persons living with HIV. J. Pain Symptom Manage., 30, 418-432.

38. Bausell, R.B., Lee, W.L. and Berman, B.M. (2001) Demographic and health-related correlates of visits to complementary and alternative medical providers. Med. Care, 39, 190196.

39. Schroeter, H., Williams, R.J., Matin, R., Iversen, L. and RiceEvans, C.A. (2000) Phenolic antioxidants attenuate neuronal cell death following uptake of oxidized low-density lipoprotein. Free Radic. Biol. Med., 29, 1222-1233.

40. Shin, J.H., Lee, C.W., Oh, S.J., Yun, J., Kang, M.R., Han, S., Park, H., Jung, J.C., Chung, Y.H. and Kang, J.S. (2014) Hepatoprotective Effect of Aged Black Garlic Extract in Rodents. Toxicol. Res., 30, 49-54.

41. Ramos, S., Alía, M., Bravo, L. and Goya, L. (2005) Compara- tive effects of food-derived polyphenols on the viability and apoptosis of a human hepatoma cell line (HepG2). J. Agric. Food Chem., 53, 1271-1280.

42. Pace, G.W. and Leaf, C.D. (1995) The role of oxidative stress in HIV disease. Free Radic. Biol. Med., 19, 523-528.

43. Hagmann, M. (2003) Study confirms effectiveness of antiretroviral drugs for HIV patients. Bull. World Health Organ., 81, 918-919.

44. Jedlinska-krakowska, M., Bomba, G., Jakubowski, K., Rotkiewicz, T., Jana, B. and Penkowski, A. (2006) Impact of oxidative stress and supplementation with vitamins $\mathrm{E}$ and $\mathrm{C}$ on testes morphology in rats. J. Reprod. Dev., 52, 203-209.

45. Goldberg, B.D. and Rabinovitch, M. (1977) Connective tissue (Weiss, L. and Greep, R.O. Ed.). McGraw-Hill Company, 145-178.

46. Hesari, A.K., Shahrooz, R., Ahmadi, A., Malekinejad, H. and Saboory, E. (2015) Crocin prevention of anemia-induced changes in structural and functional parameters of mice testes. J. Appl. Biomed., 13, 213-223.

47. Azu, O.O. (2012) Highly active antiretroviral therapy (HAART) and testicular morphology: current status and a case for a stereologic approach. J. Androl., 33, 1130-1142.

48. Arunima, S. and Rajamohan, T. (2013) Effect of virgin coconut oil enriched diet on the antioxidant status and paraoxonase 1 activity in ameliorating the oxidative stress in rats - a comparative study. Food Funct., 4, 1402-1409.

49. Lewis, W., Copeland, W.C. and Day, B.J. (2001) Mitochondrial DNA depletion, oxidative stress, and mutation: mechanisms of dysfunction from nucleoside reverse transcriptase inhibitors. Lab. Invest., 81, 777-790.

50. Azu, O.O. (2012) The male genital tract in the era of highly active antiretroviral therapy (HAART): implication for antioxidant therapy. J. AIDS Clinic. Res., 3, 169.

51. Nerurkar, P.V., Shikuma, C.M. and Nerurkar, V.R. (2001) Sterol regulatory element-binding proteins and reactive oxygen species: potential role in highly-active antiretroviral therapy (HAART)-associated lipodystrophy. Clini. Biochem., 34, 519529.

52. Carandang, E.V. (2008) Health benefits of virgin coconut oil. Indian Coconut J., XXXI, 8-12.

53. Khor, H., Rajendran, R., Gopalakrishnan, M. and Tee, E.S. (1998) The role of unsaponifiable components in the lipidemic property of olive oil. Malays. J. Nutr., 4, 81-90.

54. Calvin, H.I., Cooper, G.W. and Wallace, E. (1981) Evidence that selenium in rat sperm is associated with a cysteine-rich structural protein of the mitochondrial capsules. Mol. Reprod. Dev., 4, 139-149. 